\title{
Política social e desenvolvimento no Brasil
}

\author{
Jorge Abrahão de Castro **
}

\begin{abstract}
Resumo
Este artigo parte da compreensão de que o desenvolvimento de um país, quando pensado em uma perspectiva bem ampla, abrange muito mais do que apenas o campo econômico, incluindo também elementos da política, do social e ambiental. O Estado é peça fundamental do processo e sua política social é fonte importante de sustentação do desenvolvimento nacional, tendo conexão com todos os fatores do desenvolvimento. Para verificar a citada afirmação, buscou-se identificar e medir tais conexões para o caso brasileiro. Com os resultados obtidos, é possível comprovar o papel estratégico da política social para o desenvolvimento do país, mediante a ampliação da justiça social, do favorecimento do crescimento e da distribuição de renda, reafirmando-se como variável indispensável e estratégica não apenas para enfrentar situações conjunturais adversas como também criar alicerces da construção de uma nação econômica e socialmente mais forte e democrática.
\end{abstract}

Palavras-chave: Política social; Desenvolvimento; Justiça social; Crescimento econômico.

\section{Abstract \\ Development and social policy in Brazil}

The main argument for this paper is that a broad view of development should not be restricted to economic issues, because the idea of development also encompasses political, social and environmental elements. The state plays a key role in this process, and its social policies support national development because they are connected to all major developmental issues. In order to assess these claims, this paper seeks to identify and measure the strength of such connections in Brazil. Our results corroborate the strategic role played by social policy in fostering development by promoting social justice through income growth and redistribution. In this light, social policy is established as an indispensable variable not only for facing challenges posed by adverse circumstances, but also for creating a more just, democratic and prosperous nation.

Keywords: Social policy; Development; Social justice; Economic growth.

JEL I38.

\section{Introdução}

A ação do Estado em toda sua diversidade e complexidade tem influência e consequências nos elementos que compõem o processo de desenvolvimento de um país. A política social, como uma parte dessas ações, é uma das fontes de influência sobre o processo do desenvolvimento e, devido a sua diversidade, elemento irradiador de uma série de relações e dependências. Estas vão desde as ligadas ao campo propriamente dito social, quando pode resultar em ampliação da justiça e

** Ex-Diretor da Diretoria de Estudos e Políticas Sociais (Disoc) do Instituto de Pesquisa Econômica Aplicada (Ipea). E-mail: jorge.abrahao@ipea.gov.br, < jorge.abrahao57@gmail.com. 
coesão social, até as interações com a economia potencializando o crescimento e a produtividade, as mudanças no aparato institucional e ao ambiental entre outros.

A concepção sobre a política social sustenta-se no fato de que ela, em seu estágio mais avançado, se faz presente mediante complexos esquemas de distribuição renda, produção e provisão de bens e serviços, distribuição de ativos patrimoniais, aplicando significativas parcelas do Produto Interno Bruto (PIB) além de regular alguns setores do mercado e empregar expressiva parcela da força de trabalho do país. Em seu desenrolar, essas políticas afetam a situação social dos indivíduos, famílias e grupos sociais, induzindo melhorias na qualidade de vida da população e, ao mesmo tempo, dadas suas dimensões, alteram a economia e a autonomia de um país, o meio ambiente e o próprio patamar de democracia alcançado, tornando-se, assim, elemento fundamental para o processo de desenvolvimento nacional.

Reforça essa ideia o fato de que grande parte das experiências dos países bem-sucedidos no estabelecimento do desenvolvimento nacional contou com a consolidação e permanência no largo prazo de forte ação do Estado, a qual está, em parte, conectada ao processo de ampliação e melhoria de benefícios envolvidos nos diversos elementos constituintes das políticas sociais.

Sob tal perspectiva, este artigo demonstra algumas relações entre política social e processo de desenvolvimento no Brasil, nos primeiros anos do recente milênio. Para tanto, primeiro apresenta-se as interrelações entre a política social e os principais fatores do processo de desenvolvimento. Em seguida, procura-se dar uma dimensão concreta da política social praticada no Brasil recentemente. A seguir, busca-se demonstrar as conexões dessas políticas com o processo de desenvolvimento, mediante análise da relação entre algumas variáveis quantificáveis selecionadas. Apesar do reconhecimento da diversidade, centrou-se a análise, no momento, em apenas dois dos fatores do desenvolvimento: o social e o econômico. Por último, são apontadas algumas conclusões.

\section{Política social e desenvolvimento: conexões}

Esta seção apresenta, em seu início, a discussão que embasou a definição de política social a ser trabalhada no decorrer do artigo e, em seguida, a discussão sobre as principais relações entre essas políticas e o processo de desenvolvimento. Para tanto, foi norteadora a ideia de que o processo de desenvolvimento de um país abrange muito mais que apenas o campo de reflexão da economia, incluindo também elementos relativos à análise das instituições, das relações sociais, políticas e mais recentemente ambientais entre outros campos do conhecimento. Referindo-se à teoria do desenvolvimento econômico, Furtado (1961) já alerta que tal teoria: 
não cabe, nos termos gerais das categorias de análise econômica. (...) A análise econômica não nos pode explicar a dinâmica das mudanças sociais senão de maneira limitada. Contudo ela pode identificar alguns mecanismos (relações estáveis entre variáveis quantificáveis) do processo de desenvolvimento econômico (Furtado, 1961).

As concepções a respeito da política social estão expressas em uma literatura extensa e variada e as visões em torno da ação estatal na área, além de serem numerosas, não apresentam consenso conceitual. Marshall (1967) diz que: "Política Social é um termo largamente usado, mas que não se presta a uma definição precisa. O sentido em que é usado em qualquer contexto particular é em vasta matéria de conveniência ou de convenção". Não existe um consenso para a caracterização de política social e um dos fatos relevantes para isso é que nenhum modelo teórico isenta-se de apresentar problemas. A definição de um conceito único é uma tarefa em grande medida subjetiva e, muitas vezes, impossível. Em tal sentido, após uma análise cronológica das principais - e secundárias - abordagens teóricas, Coimbra (1987) conclui que:

(...) sequer uma definição adequada do que é política social existe nas principais abordagens (...), todas as abordagens teóricas ao estudo da política social, por mais diferentes que sejam umas das outras, se igualam na adoção de definições puramente somatórias, pobres teoricamente e muito insatisfatórias metodologicamente (Coimbra,1987).

Na ausência de um conceito inequívoco de política social, então, as concepções adotadas por pesquisadores e formuladores de políticas estão preocupadas tanto com aspectos teóricos, mas, em muitos casos, também ligadas à prática concreta das políticas. Grande parte das reflexões sobre a política social varia, por isso, conjunturalmente e é reflexo das condições e problemas sociais vigentes em cada país, não significando que a discussão sobre o tema torna-se irrelevante em termos teóricos.

A bibliografia internacional, por exemplo, em grande medida, vinha concentrando-se no entendimento e análise da experiência europeia, tendo em vista o elevado grau de desenvolvimento de suas economias e os avanços, em termos comparativos, na discussão da consolidação dos direitos sociais e sistemas de proteção social ${ }^{1}$. Ademais, o debate sobre política social mistura-se às diversas interpretações analíticas da lógica e evolução dos Welfare State ${ }^{2}$, porque a política social é uma ferramenta primordial utilizada pelo Estado para gerar bem-estar social e as várias formas e possibilidades de implementação dessa ação levam a diferentes tipos e/ou padrões de atuação governamental na resolução das questões sociais ${ }^{3}$.

\footnotetext{
(1) Ver Flora e Heidenheimer (1981); Flora (1986); Baldwin (1990).

(2) Expressão inglesa para expressar a ideia de Estado de Bem-estar.

(3) Ver Titmus (1963); King (1988); Esping-Andersen (1991); Gough (2000); Castel (1998); Draibe e Aureliano (1989); Draibe e Henrique (1988); Arretche (1995).
} 
O surgimento e aprimoramento das políticas sociais latino-americanas viabilizaram algumas importantes considerações mais ajustadas às realidades de países em desenvolvimento ${ }^{4}$. No Brasil, embora ainda haja carência de referências empíricas e teóricas, também se verificou um crescimento significativo de estudos e pesquisas conexos nos últimos anos, demonstrando aumento de interesse no debate sobre o papel do sistema de proteção social e das políticas sociais brasileiras no atendimento às carências e demandas sociais ${ }^{5}$.

Considerando as citadas ponderações da literatura especializada e tendo em vista os objetivos do artigo, é um passo fundamental adotar um conceito organizador do que será entendido por política social para, em seguida, buscar a conexão com os principais elementos do processo de desenvolvimento. Essa tarefa é mais complicada do que parece à primeira vista, pois as políticas públicas têm aspectos bastante dinâmicos uma vez que em sua trajetória histórica cada sociedade incorpora o reconhecimento de determinadas contingências, necessidades e riscos, exigindo que o Estado e outros entes sociais assumam a responsabilidade pela solução, no curto e longo prazo. Tais processos constituem, em cada país, políticas com maior ou menor abrangência e com características próprias, estando na maior parte do tempo em construção ou em reforma. Compreende-se, a partir daí, por que elaborar uma definição de política social é uma tarefa complexa.

Apesar de todas as dificuldades e limitações irá adotar-se aqui o entendimento da política social como sendo composta por um conjunto de programas e ações do Estado que se concretizam na garantia da oferta de bens e serviços, nas transferências de renda e regulação de elementos do mercado. Para tanto, a política social busca realizar dois objetivos conjuntos que são a proteção social e a promoção social para dar respostas aos direitos sociais ${ }^{6}$ e a outras situações não inclusas nos direitos as quais dizem respeito às contingências, necessidades e riscos que afetam vários dos componentes das condições de vida da população, inclusive os relacionados à pobreza e à desigualdade. Ademais, a oferta de bens e serviços similares aos oferecidos pelo Estado pode ser fornecida por entidades privadas sejam lucrativas ou não.

A proteção social dos cidadãos manifesta-se na seguridade social que tem como ideia força a solidariedade (apesar do critério do seguro social ainda prevalecer

(4) Ver Cepal (2000; 2007); Espiná (2008); Cepal (2008).

(5) Ver Santos (1979); Draibe e Aureliano (1989); Jaccoud (2005); Castro, J. et. al. (2008); Ipea (2007; Ipea (2010a; 2010f).

(6) Para Esping-Andersen (1991), "a introdução dos direitos sociais modernos, por sua vez, implica um afrouxamento do status de pura mercadoria dos indivíduos.” Para Marshal (1967), os direitos sociais corresponderiam ao direito a um mínimo de bem-estar econômico, ao direito de participar, por completo, na herança social e levar a vida de um ser civilizado de acordo com os padrões que se estabelecem na sociedade. 
em grande parte dos países) ${ }^{7}$ aos indivíduos, famílias e grupos em determinadas situações de dependência ou vulnerabilidade, entre as quais se podem citar: (a) incapacidade de ganhar a vida por conta própria em decorrência de fatores externos, que independem da vontade individual; (b) vulnerabilidade devido ao ciclo vital do ser humano - crianças e idosos, por exemplo; (c) situações de risco, como em caso de acidentes - invalidez por acidente etc.

A promoção social é entendida como a resultante da geração de igualdades, oportunidades e resultados para indivíduos e/ou grupos sociais. A ideia força é que a geração de igualdades está relacionada à expansão da oferta de bens e serviços sociais, enquanto bens equalizadores providos pelo poder público, principalmente a escolarização e o acesso à saúde como elementos centrais na geração de habilidades e capacidades em indivíduos e/ou grupo social. Apenas isso, no entanto, não é suficiente para garantir a geração de igualdade, sendo necessário também garantir por meio das políticas públicas, o exercício de tais capacidades, mediante as políticas de inclusão produtiva de diversos tipos e padrões, seja no meio rural ou nas cidades. São eles elementos primordiais para promoção social, pois permitem a ampliação de oportunidades e a obtenção de melhores resultados pessoais e coletivos. Tal pressuposto só vai ser atingido se, em seu processo de universalização, conseguir atingir as populações mais pobres com bens e serviços de boa qualidade ${ }^{8}$.

De acordo, portanto, com as condições históricas estruturais de cada país e sua situação e contexto presente, o formato e a amplitude da implementação dos elementos geradores da seguridade social e igualdade de oportunidade e de resultado vão ter influência direta na direção tomada pela política social, trazendo como resultante a ampliação da justiça social e a coesão social possíveis no país, o que pode representar maior equidade ${ }^{9}$.

Examinar apenas as citadas variáveis não permite uma leitura do estágio de desenvolvimento do país, como foi mencionado anteriormente. Nesse sentido, a Cepal (2007) chama a atenção para que a análise da "política social debe concebirse dentro de las possibilidades del dessarollo econômico, pues los beneficios sociales, para sean reales, tienen um costo que debe financiarse adecuadamente". Também, é importante observar o que é sugerido por Alcock (1966) "understanting of social policy thus requires an understanding of the economic policy context in which social policies develop and of the interrelationship between changes in economic and social policy".

(7) Para o caso brasileiro, ver Teixeira (1992); Fleury (2005); Vianna (1998); Sposati (2009).

(8) A respeito desse tipo de abordagem, ver Sen (2001; 2009; 2011); Rawls (1992), Cepal (2007) e Delgado e Theodoro (2005).

(9) Para a Cepal (2007), é a busca de maior equidade que "requiere que las sociedades creen sistemas de protección y promoción de las oportunidades y la calidad de vida em aspectos que consideren de valor social, y que permitam a todos los ciudadanos a ser partícipes de los beneficios y atores del desarrollo". 
Seguindo a perspectiva mencionada, é possível estabelecer um determinado tipo de conexão que ocorre entre as políticas sociais e os fatores econômicos, principalmente, quando o gasto autônomo com as políticas sociais torna-se elemento importante a ser considerado para o ritmo de expansão da atividade econômica, o que vai depender muito de sua dimensão e forma de distribuição. É importante qualificar e tentar dimensionar até que ponto tais políticas podem afetar tanto a demanda agregada e a produtividade da economia. Esse tipo de enfoque segue Furtado (1961, 1992, 2011), Tavares (1998a, 1998b). Mais recentemente, na mesma perspectiva, o Ipea (2010f) e os trabalho de Amitrano (2011) e Bruno et al. (2009) são interessantes por buscarem uma abordagem específica ao estudo do crescimento econômico de médio e longo prazo que leva em conta elementos de demanda, de oferta e fatores institucionais, bem como a interação entre eles.

Quanto aos aspectos relativos à demanda agregada à interação ocorre quando o gasto público com as políticas sociais permite a ampliação do sistema de garantia de renda (monetária ou não monetária), enquanto elemento importante na geração de um determinado tipo de distribuição pessoal e funcional da renda ${ }^{10}$ e seu respectivo padrão de consumo dos indivíduos, famílias e grupos. Em sociedades heterogêneas, quanto mais amplas forem as rendas manejadas e destinadas às camadas mais pobres, maior a capacidade de alteração do padrão, gerando a possibilidade de ampliação da demanda agregada, com capacidade de criar um amplo mercado interno de consumo ${ }^{11}$. Em contrapartida, também é importante para a economia a garantia da oferta de bens e serviços sociais, pois, para sua implementação, trazem consigo a necessidade do aumento dos gastos na contratação de pessoal, construção, manutenção e equipamentos em escolas, hospitais, postos de saúde, compra de livros, medicamentos e outros insumos estratégicos etc.

No que diz respeito à produtividade, argumenta-se que a política social, principalmente quanto à ampliação das habilidades, capacidades e inclusão produtiva da população, é também, um elemento central para o aumento da inovação e produtividade do trabalho, fatores decisivos para o crescimento econômico, além de facilitar a elevação dos salários e a queda da pobreza. Ademais, também pode

(10) De acordo com Cepal (2000), "El gasto público social es el principal instrumento a través del cual el Estado influye sobre la distribuición del ingresso..(...) dicho impacto dependerá de la magnitud del gasto social, su distribuición y financiamiento, así como de la eficiencia em el uso de los recursos correspondiente"

(11) "A hipótese de que os recebimentos de renda de cidadania transformam-se em gasto em bens de consumo popular, equipara a assertiva 'os trabalhadores gastam o que ganham', numa outra equivalente: 'os pobres gastam o que ganham'. Esta tese nos leva, admitindo o princípio da demanda efetiva (sentido de determinação da renda e produto pelas variáveis de gasto macroeconômico), a atribuir sentido causal ao gasto social. A causalidade aqui tem a ver com as variações de curto prazo do gasto social, co-determinando[sic] a renda dos familiares pobres e sustentando a produção e o consumo popular de bens-salários” (Delgado; Theodoro, 2005). 
significar melhor distribuição de renda com queda da desigualdade, a depender, no caso, do que tenha resultado em termos de ampliação da renda do fator trabalho ${ }^{12}$.

Para o entendimento do processo de desenvolvimento, da mesma forma, é relevante considerar o contexto institucional e Evans (2010) chama a atenção que "tanto os teóricos quanto os formuladores de políticas não podem ignorar o papel fundamental das instituições estatais na criação bem-sucedida do desenvolvimento". Como adverte Chang (2004, contudo, não deixando de considerar que muitas instituições atualmente tão imprescindíveis ao desenvolvimento são mais a consequência do que causa do desenvolvimento econômico e social das nações. Nesse sentido, todo o circuito de elaboração e implementação das políticas públicas envolvidas na montagem do aparato das políticas sociais é produto das tensões políticas, sociais e econômicas latentes na sociedade. Por sua vez, também é fonte de grande aprendizado institucional, demandando grande esforço da sociedade e do aparato estatal, que estará em constante transformação. Ademais, as políticas sociais ao permitirem a ampliação das habilidades e capacidades dos indivíduos, famílias e grupos podem ser elemento importante para melhoria da compreensão dos processos econômicos, sociais e políticos pelos quais o país passa. Consequentemente, podem ser elemento para ampliação da participação política e social e maior defesa e ampliação da igualdade e solidariedade social como princípio e pilar da estruturação da sociedade, fomentando alterações nas instituições estatais fundamentais aos processos de desenvolvimento.

Por último, outra relação também importante a ser considerada no processo de desenvolvimento são aquelas relativas às conexões entre políticas sociais e o contexto ambiental. No que diz respeito às questões ambientais, a política social pode e deve cumprir papel relevante quando da elaboração e implementação de suas políticas, buscando a recuperação e preservação do meio ambiente como critério para desenho de próprias ações. Em contrapartida, os problemas ambientais, quando de suas ocorrências, atinge fortemente as populações mais pobres, forçando ainda mais a necessidade de ampliação das políticas socais.

Observar, portanto, os mencionados fatores conjuntamente e suas interrelações e implicações permite melhor compreensão do estágio de desenvolvimento que determinado país pode estar vivendo. É importante, contudo, salientar que os

(12) Nessa mesma perspectiva, a Cepal no começo da década de 1990 já expressava preocupação com o tema: "A fim de melhorar a produtividade nos setores atrasados, e como complemento às políticas agregadas, parece imprescindível empreender algumas ações específicas, entre elas programas de crédito, comercialização e assistência técnica, bem como um investimento maciço na formação e na qualificação. O esforço de modernização tecnólogica é crucial, não apenas pelas exigências da competitividade internacional, mas também pela necessidade de melhorar a qualidade dos empregos e os níveis salariais" (Cepal, 1992). 
encadeamentos são previstos no plano teórico, mas precisam ser coadunados com o mundo real, observando-se o estágio de cada país e das trajetórias históricas, pois cada sociedade, dependendo das lutas políticas, irá incorporar o reconhecimento de determinadas necessidades sociais e igualdades desejáveis. Assim, exigirá que o Estado assuma a responsabilidade pela produção, provisão e regulação de sua defesa e promoção. Tais processos constituem, nos países separadamente, processos diferenciados com maior ou menor abrangência, mas dinâmicos, estando na maior parte do tempo em construção.

\section{Política social brasileira}

A política social no Brasil, apesar da atual amplitude é, ainda, marcada por políticas específicas com baixa coordenação entre elas e grandes desafios em termos de abrangência (universalidade e integralidade) e qualidade dos bens e serviços oferecidos. Nesse sentido é que se percebe a dificuldade de pensar a política social brasileira na perspectiva da ideia do Welfare State ou mesmo discutir a validade de tal conceito para enquadrar os esquemas vigentes atualmente. A própria literatura nacional da área reflete a realidade atual da política social, uma vez que ela é também bastante setorial, tratando de políticas específicas e com predominância, em termos metodológicos, da análise voltada para descrição dos estágios alcançados e/ou deficiências reveladas.

Para efeito da análise da política social e suas conexões com o processo de desenvolvimento, será adotado um conceito organizador da política social como sendo o conjunto de políticas, programas e ações do Estado, com objetivo de efetuar a proteção e a promoção social em repostas aos direitos sociais e a outras situações não inclusas nos direitos referentes às contingências, necessidades e riscos que afetam vários dos componentes das condições de vida da população. Tais programas e ações concretizam-se na garantia da oferta de bens e serviços, transferências de renda e regulação de elementos do mercado.

Para atingir os objetivos mencionados, o Estado brasileiro atualmente desenvolve um conjunto diversificado de políticas públicas apresentadas resumidamente na Figura 1. Para dar resposta ao objetivo - proteção social -, agrupam-se as políticas sociais vinculadas à Seguridade Social. Políticas destinadas a reduzir e mitigar as contingências, necessidades e riscos a que qualquer indivíduo está exposto em uma sociedade de mercado, tal como o de não poder prover seu sustento e da família por meio do trabalho, seja por velhice, morte, doença ou desemprego: essa categoria engloba os diferentes programas e ações da Previdência Social (aposentadorias, pensões e auxílios) geral e do setor público, Saúde, Assistência Social e Seguro-Desemprego. 
Figura 1

Políticas setoriais e transversais da política social brasileira - 2010

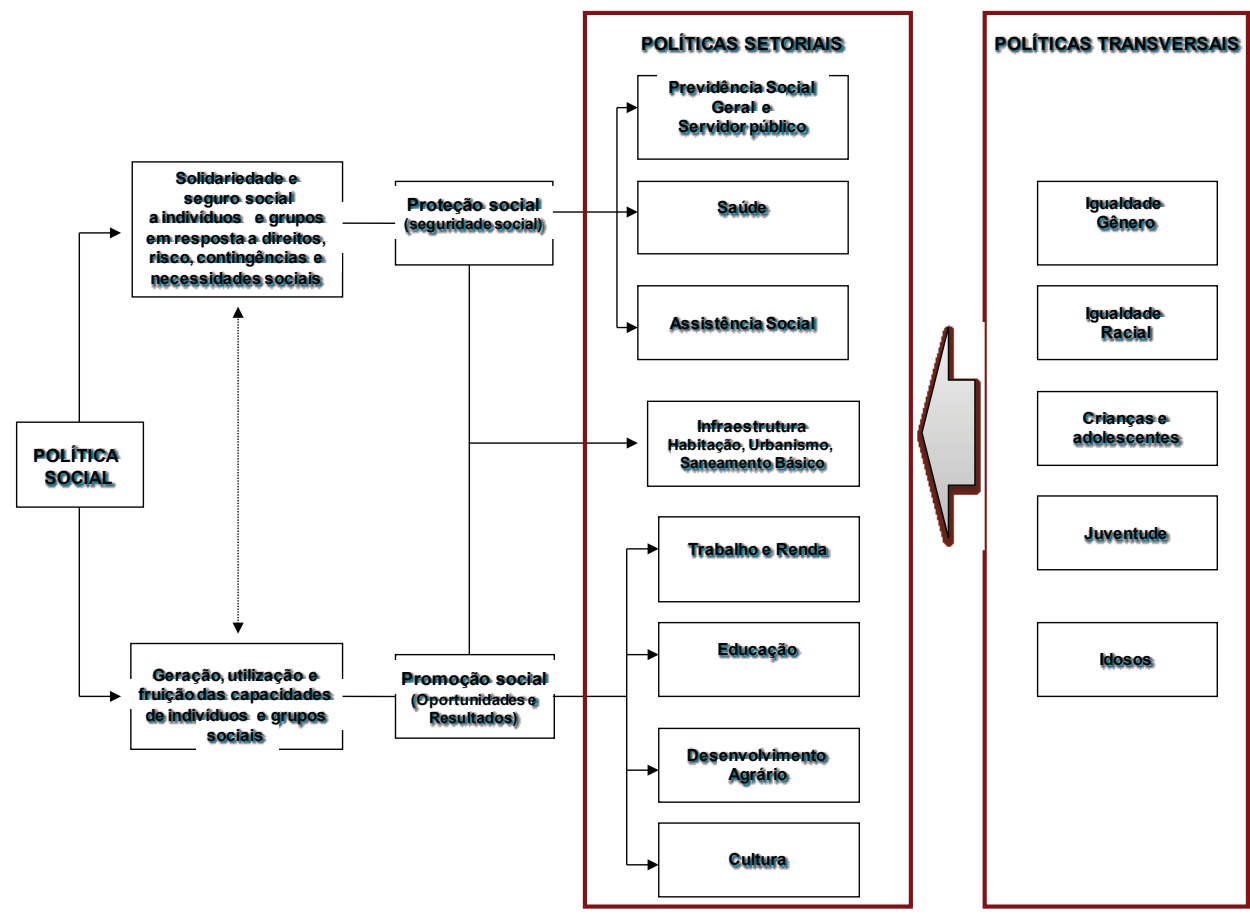

Fonte: IPEA (2010a) - Elaboração própria .

Para o objetivo - promoção social -, agrupam-se as políticas que, a partir de determinados instrumentos, pretendem garantir aos cidadãos oportunidades e resultados mais amplos e equânimes de acesso aos recursos e benefícios conquistados pela sociedade em seu percurso histórico. Tais políticas compreendem um vasto espectro de ações que abarca desde a formação e desenvolvimento do cidadão - casos da Educação, do acesso à Cultura e das políticas de Trabalho e renda que buscam a qualificação profissional e regulação do mercado de Trabalho -, até a democratização do acesso a ativos - como as políticas voltadas à Agricultura Familiar (acesso a crédito, extensão rural, reforma agrária), à Economia Solidária, à Habitação, à Mobilidade Urbana.

Além das políticas mais tradicionais, desenvolvem-se uma série de políticas de corte transversal que podem ter caráter tanto de proteção quanto de promoção social, semelhante às ações voltadas à igualdade de gênero e racial, assim como as destinadas especificamente às etapas do ciclo de vida, conforme as políticas voltadas para as crianças, adolescentes, juventudes e idosos. 


\subsection{Abrangência da política social brasileira}

A Política Social brasileira, hoje, chama a atenção pela dimensão de seu conjunto: são centenas dos mais diferentes tipos de beneficios ofertados diariamente a dezenas de milhões de cidadãos atingidos pelas ações e programas implementadas pelas diversas políticas públicas de proteção e promoção social. Destaque-se, ainda, que tais políticas não se apresentam fragmentadas em ações emergenciais ou descontínuas, mas, ao contrário, operam de modo estável e sustentado no tempo, com regras e instituições estabelecidas. Boa parte dos benefícios e serviços têm estatuto de direitos e exigem capacidade instalada, com aplicação diária de recursos materiais, humanos e financeiros em sua produção e provisão, ainda que nem sempre no volume e na qualidade desejados.

As políticas públicas que buscam atingir os dois grandes objetivos mencionados no item anterior circunscrevem-se no interior de organismos estatais minimamente preparados para efetuar uma série de ações e programas de três tipos básicos: i) garantia de renda; ii) garantia da oferta de bens e serviços sociais; iii) regulação. As duas primeiras ocorrem principalmente mediante expressivos gastos públicos pelo aparato do estado e a última envolve poucos recursos financeiros. Esses tipos estão detalhados na Figura 2.

As políticas de garantia de renda ocorrem, em especial, a modalidade transferências monetárias em que as mais comuns são as aposentadorias, pensões, seguro-desemprego, auxílio monetário à família. Utilizam-se transferências em dinheiro que os beneficiários têm liberdade de gastar no mercado segundo suas preferências, sem restrições ou determinações políticas. Essas, contudo, como no caso do Programa Bolsa Família (PBF), podem não ser transferências incondicionadas, uma vez que os indivíduos necessitam cumprir certos requisitos para beneficiarem-se de alguns programas. Existem também ações de Garantia de Renda não monetárias que buscam ofertar condições aos indivíduos e grupos para que possam gerar sua própria renda, tal como o Programa Nacional de Fortalecimento da Agricultura Familiar (Pronaf).

Os números dos beneficiários envolvidos nesse tipo de política são bastante expressivos, como pode ser constado de forma bem resumida na Figura 2. No Regime Geral de Previdência Social (RGPS), por exemplo, são distribuídos mensalmente cerca de 28 milhões de benefícios e, no Regime Público de Previdência Social (RPPS), cerca de 4,3 milhões de benefícios, ou seja, somente os dois regimes distribuem cerca de 32,3 milhões de benefícios. Grande parte deles são superiores ao Salário Mínimo (SM) e absorvem 11,5\% do PIB. Ademais, o Beneficio de Prestação Continuada (BPC) da assistencia social atende a 3,3 milhões de pessoas, sendo 1,8 milhões de pessoas com deficiências e 1,5 milhão de idosos. A transferência direta de renda associada à política de assistência social ainda é composta pelo Programa 
Bolsa Família (PBF), voltada a famílias em situação de grande vulnerabilidade. Sua relevância reside especialmente na extensão da população que alcança (mais de 13,4 milhões de famílias, 2012), com recursos disponibilizados de forma contínua. Estima-se que esse programa alcance cerca de 50 milhões de pessoas.

Figura 2

Tipo de políticas envolvidas da política social brasileira - 2010

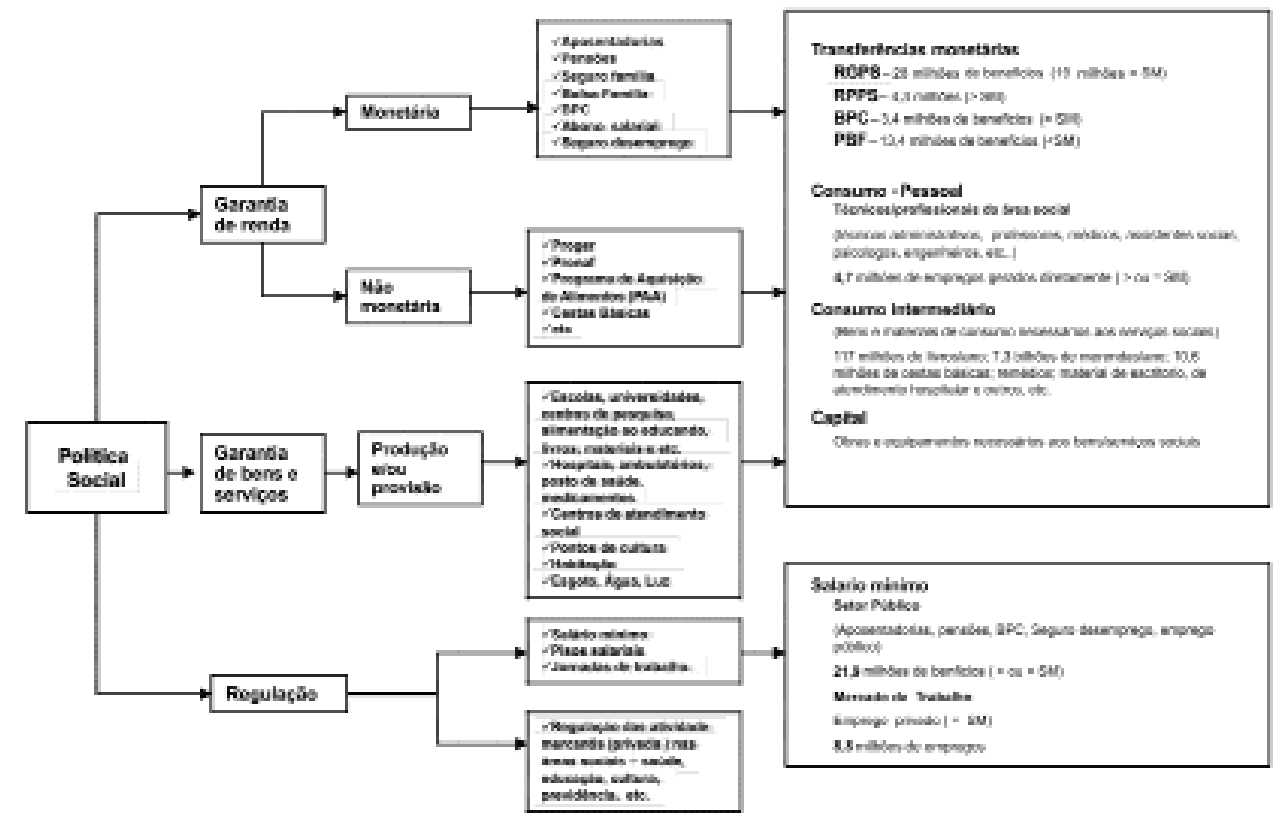

Fonte: Ipea (2010a) e Ipea/Ipeadata. Elaboração própria

Além desse vetor da política social outro vetor importante é o da Garantia da oferta de bens e serviços sociais que ocorrem de duas formas: i) Produção: implica a participação direta de organismos estatais na fabricação de bens e oferta de serviços (exemplo: educação pública, saúde); ii) Provisão de bens e serviços: implica, por parte do Estado, arbitrar os recursos financeiros para viabilizar bens e serviços à comunidade (a provisão pública não requer necessariamente produção pública - por exemplo, o Estado pode garantir, por meio do financiamento público, o atendimento a um paciente que necessite de uma cirurgia a ser realizada somente em hospital particular. Essa separação requer, contudo, adequada regulação e fiscalização da produção privada para não se afastar das metas fixadas pelas autoridades públicas).

Na citada ação da política social, ganha relevância a política de educação mediante a inclusão de grupos populacionais cada vez maiores nas escolas e universidades, em condições que, se ainda longe das ideais, melhoraram nos últimos anos. Pode-se dizer que, o número de matrículas ampliou-se em todos os níveis educacionais. Para tanto, conta com serviços públicos estruturados de alfabetização, 
educação básica, educação superior e pós-graduação. O número escolas disponíveis no sistema chega próximo a 180 mil. Ademais, na educação básica estão empregados cerca de 2 milhões de professores - dos quais 1,6 milhão na rede pública. No ensino superior, são quase 340 mil docentes - 120 mil em instituições públicas. Este aparato físico e humano faz-se acompanhar da distribuição de alimentos e refeições, livros e materiais didáticos, serviços de transporte escolar, acesso aos meios digitais de aprendizagem e à internet para alunos da rede pública da educação básica.

Na área da política de Saúde, a instituição do Sistema Único de Saúde - SUS, promoveu a unificação dos serviços públicos da área, assim como a universalização do acesso a eles. Também, organizou sua oferta de forma descentralizada, com a participação pactuada dos diversos níveis de governo: união, estados e municípios. A prioridade a Atenção Básica, incorporou às suas responsabilidades, atividades de vigilância sanitária e epidemiológica, assistência farmacêutica e promoção da saúde bucal. Com a introdução do programa Saúde da Família - principal instrumento da política de Atenção Básica - a cobertura à saúde foi significativamente ampliada, em especial, nos municípios e localidades distantes dos grandes centros. Merecem destaque mais recente a contínua ampliação do Programa Nacional de Imunização e iniciativas como o Serviço de Atendimento Móvel de Urgência (SAMU). Em termos de benefícios oferecidos, observa-se que o SUS realiza, em média, 2,3 bilhões de procedimentos ambulatoriais por ano, ou seja, 11 mil transplantes, 215 mil cirurgias cardíacas, 9 milhões de procedimentos de quimioterapia e radioterapia e 11,3 milhões de internações . Tanto na linha da atenção básica quanto na de medicamentos mais complexos, o SUS tem contribuído, com maior ou menor êxito, para ampliar o acesso a remédios e tratamentos.

As demais políticas voltadas à garantia de bens e serviços, como apresentado no esquema da Figura 2, tem-se a Habitação e Saneamento. Atualmente, vem fortalecendo seu aparato institucional com a criação de um ministério que tem a responsabilidade de tocar as ações e programas e um agente de fianciamento das ações como a Caixa Economica Federal, além de ter programa de grande prioridade em implementação. Já, na área do desenvolvimento agrário, apesar de não se constituir em sistema, está desenvolvendo um esquema de gestão e organização da política voltada para seu público alvo intitulado territórios da cidadania, mas ainda em processo de experimentação.

Por último, tem-se a Regulação baseada na fixação de normas que regulem o comportamento dos agentes econômicos privados e públicos - um exemplo de mecanismo regulador é o controle de qualidade sobre a produção e a comercialização de medicamentos, alimentos, etc. As políticas de regulação estão ganhando importância crescente no papel a ser desempenhado pelo Estado, mas ainda constituem-se práticas recentes, por isso os gastos do tipo de ação referemse apenas à manutenção das atividades do órgão regulador. Neste âmbito, ressalta a política de Salário Mínimo (SM) que corresponde às determinações estatais 
relacionadas ao Piso salarial legal, com influência sobre o mercado de trabalho. No caso Brasileiro, no entanto, tem importância também como elemento determinante do valor dos benefícios previdenciários (pensões e aposentadorias) e da assistência social e do seguro desemprego. A quantificação da influência do SM para o ano de 2009 mostra, no que diz respeito às ações do Estado, uma influência direta de 21,9 milhões de benefícios sociais todos os meses. Ademais, quando são computados todos os valores conjuntamente, observa-se que os gastos com esses beneficios podem chegar a 4,5\% do PIB brasileiro. A influência da regulação direta do SM, no mercado de trabalho, mostra que o SM tem influência crescente e vai impactar diretamente no salário de 8,8 milhões de pessoas, em 2009, que representa cerca de $10 \%$ da PEA ocupada. Além do mais, ao computarem-se todos os valores, observase que esses salários, quando agregados, podem representar $1,6 \%$ do PIB brasileiro.

\subsection{Gasto público com a Política Social}

A manutenção desse conjunto de políticas públicas exige, de modo lógico, a mobilização de recursos fiscais compatíveis. O patamar dos gastos sociais no Brasil vem sendo significativamente alterado desde o final dos anos 1980. Sobretudo a partir de 1993, com o efetivo início da implementação das políticas previstas pela Constituição Federal de 1988 - SUS, Lei Orgânica da Assistência Social (Loas), Previdência Rural entre outras -, os gastos sociais passam a aumentar de maneira sustentada. Refletindo tal tendência, os dados apresentados no Gráfico 1 apontam uma tendência de crescimento do Gasto Público Social (GPS) ${ }^{13}$, de 6,0 pontos percentuais (p.p.) do PIB entre os anos de 1995 e 2010. Esse crescimento é fortemente ancorado na ampliação dos gastos da esfera federal que subiram cerca de 4,1 p.p. do PIB. O crescimento de 0,7 p.p. do PIB no gasto social estadual e cerca de 1,2 p.p. do PIB no gasto social municipal refletem uma tendência fortalecimento do gasto da esfera municipal.

Gráfico 1

Gasto Público Social (GPS) por esfera de governo em \% do PIB-1995 e 2010

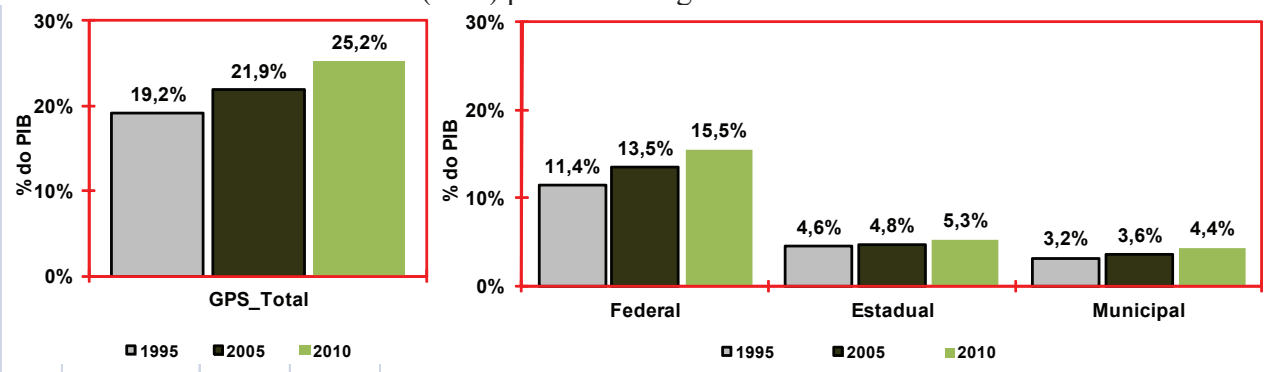

Fonte: Castro (2008) e Sistema Integrado de dados Orçamentarios (Sidor) do MPOG.

(13) O Gasto Público Social (GPS) compreende os recursos financeiros brutos empregados pelo setor público no atendimento de demandas sociais o qual corresponde ao custo de bens e serviços - inclusive bens de capital - e transferências, sem deduzir o valor de recuperação - depreciação e amortização dos investimentos em estoque ou recuperação do principal de empréstimos anteriormente concedidos. 
Tomando-se o volume de recursos, apresentado no Gráfico 2, observa-se que o núcleo da política social foi permanentemente localizado ao longo do tempo nas políticas sociais de Previdência Social Geral, Previdência e Benefícios a Servidores Públicos, Saúde, Assistência Social, Educação e Trabalho e Renda. Juntas, as seis áreas absorvem algo em torno de 95,0\% do gasto no período de 1995 a 2010. Já, a participação de cada uma dessas políticas no montante do gasto social modifica-se durante o período, como pode ser observado no Gráfico 2, a seguir.

Gráfico 2

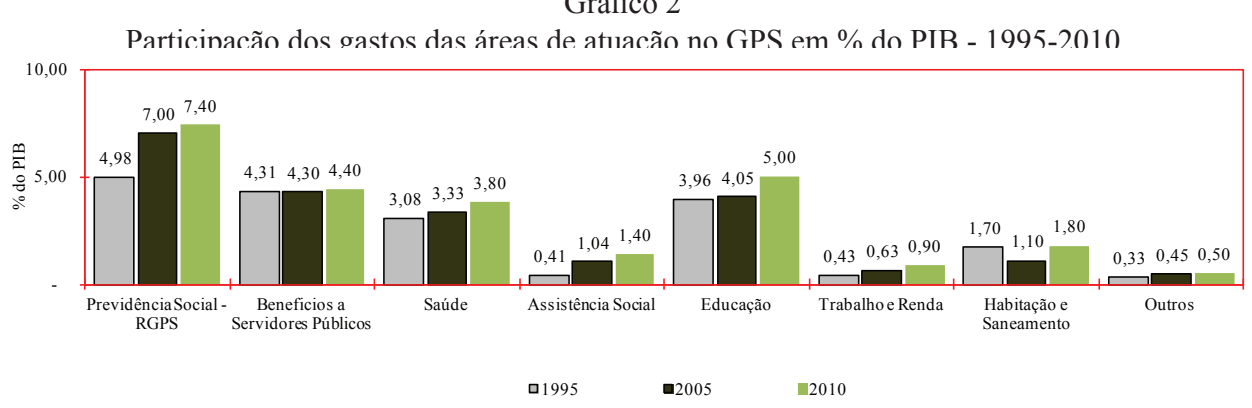

Fonte: Castro (2008) e Sistema Integrado de dados Orçamentarios (Sidor) do MPOG.

Os gastos com o RGPS apresentaram um crescimento maior que as demais áreas, a ponto de elevar a participação no PIB de 4,98\% para 7,40\%, mas, por sua vez os gastos com o RPPS variou pouco de $4,31 \%$ para $4,40 \%$. Nesse sentido, a composição dos gastos previdenciários parece ter melhorado entre 1995 e 2010 . A parcela aplicada nos benefícios do RGPS, que são redistribuidores de renda, elevouse, ao passo que a parcela destinada aos gastos com Previdência e Benefícios a Servidores Públicos, que são concentradores de renda, ficou estável. Tal constatação sobre o volume agregado de recursos envolvidos no RGPS e nos RPPS não subestima a intensa agenda de discussão que persiste como central para a readequação dos dois sistemas.

A área de maior crescimento relativo em termos de importância no conjunto dos gastos sociais foi a de Assistência Social (de 0,40\% do PIB, em 1995, para $1,40 \%$, em 2010), consequência direta da drástica reformulação dessas políticas públicas no período, com a substituição de um modelo "assistencialista" por um modelo de direitos - com uma atuação cada vez mais abrangente sobre a população brasileira, sendo que mais recentemente entrou em curso nova ampliação com a criação do Bolsa-Família e a implantação do Sistema Único de Assistência Social (SUAS).

A trajetória dos gastos nas políticas públicas de Educação e de Saúde foi outra. As áreas referidas, quando medidas em termos de percentual do PIB, não cresceram em importância no período entre 1995 e 2005. Embora em termos absolutos recebam atualmente muito mais recursos do que antes, seus gastos apenas acompanharam o crescimento da economia, não se revelando como prioridade de 
governo, de tal modo que as respectivas parcelas do gasto social destinadas à Saúde e Educação foram quase iguais aquelas verificadas em 1995. A partir de 2005 até 2010, no entanto, verificou-se um crescimento em ambas áreas. Na educação, a ampliação foi maior, cerca de $4 \%$ do PIB para 5\% do PIB (cerca de um acréscimo de $1 \%$ do PIB). Já, na saúde, o crescimento foi menor com acréscimo de $0,5 \%$ do PIB. Enquanto isso, a saúde privada mobilizou recursos da ordem de 4,7\% do PIB no mesmo ano, ou seja, para atender uma parcela da população que paga por seu atendimento médico a planos de saúde e outros provedores de serviços - em torno de $21 \%$ da população -, destina-se um volume de recursos superior ao aplicado nos serviços públicos de saúde - que são universais e cobrem toda a população.

Quando se observar a trajetória de gastos das áreas de Saneamento e de Habitação e Urbanismo, verifica-se que até 2005 houve redução de recursos aplicados. Mesmo com todas as discrepâncias metodológicas existentes entre os trabalhos de onde foram extraídos os dados para cada período - que, certamente, geram algum nível de imprecisão nas comparações aqui realizadas - a redução drástica nas aplicações de recursos em tais políticas públicas, é inegável no período. Desde essa data até 2010, no entanto, observa uma grande recuperação no gastos da área que sobem de $1,1 \%$ do PIB, em 2005, para 1,8\%, em 2010, maior valor gasto na área em todo o período analisado

\subsection{Financiamento da política social}

A partir da Constituição Federal de 1988 (CF 88), a responsabilidade pública no financiamento da política social foi significativamente expandida, o que trouxe como consequência aumento dos gastos. Para fazer frente às despesas geradas pelos serviços e benefícios ofertados, era preciso proceder à alteração dos sistemas de financiamento e gestão das políticas sociais. Para tanto, a CF 88 previu a criação do "Orçamento da Seguridade Social" e do "Ministério da Seguridade Social", destinados a promover a integração dos recursos e ações das antigas pastas da Saúde, Previdência e Assistência Social. Ademais, manteve as vicunlações para a Educação. O processo de regulamentação da Seguridade Social seguiu, todavia, caminho distinto do previsto, isto é, os ministérios não foram unificados e o desempenho pujante do Orçamento da Seguridade em termos da arrecadação gerada por suas contribuições sociais não se refletiu em um crescimento de mesmo ritmo na destinação de recursos às áreas sociais.

O novo arranjo das relações federativas promovido pela Constituição de 88 que redistribuiu entre os entes federados a oferta e gestão de importantes serviços sociais públicos, seria acompanhado pelo aumento de receitas vinculadas, assim como de transferências de recursos da União, para estados e municípios, aumentando a capacidade destes para financiar o gasto social e reduzindo sua dependência em relação à União. Na primeira metade dos anos 90, contudo, para dotar de maior flexibilidade o processo de alocação de receitas públicas, foi criado um sistema de desvinculação de recursos denominado Desvinculação de Receitas 
da União (DRU). O mesmo passou a destinar 20\% das receitas arrecadadas em nome das políticas sociais para o atendimento de outras prioridades fiscais, como a geração de superávits primários. Isso acabou por desorganizar a estrutura de financiamento social, uma vez que subtraiu recursos de seu Orçamento e permitiu uma reconcentração na distribuição da receita tributária disponível a cada nível de governo - sem, no entanto, sequer se aproximar dos níveis de concentração vigentes antes da Constituição - prejudicando principalmente os estados.

Assim, ainda é considerável a dependência político-financeira dos entes subnacionais junto ao governo federal, visível por exemplo em sua necessidade de recorrer a transferências negociadas. Essa configuração mantém em mãos do governo central um forte instrumental para influenciar a montagem dos serviços locais, não só pela regulação mas também por meio de incentivos e contrapartidas financeiras. Destarte, o avanço da descentralização das políticas sociais, bem como a redução das desigualdades entre municípios, estados e regiões brasileiras estão ainda dependendo de um novo arranjo fiscal na federação, que avance na direção de um federalismo mais cooperativo.

Além da perda de recursos causada pela DRU e dificuldades impostas pelo anacronismo do atual pacto federativo, uma outra questão que constitui grave desafio ao avanço da situação social brasileira diz respeito à regressividade da carga tributária brasileira a ser comprovada no Gráfico abaixo.

Gráfico 3

Tributação total e participação dos tributos diretos e indiretos na renda total das famílias no Brasil 2008-2009
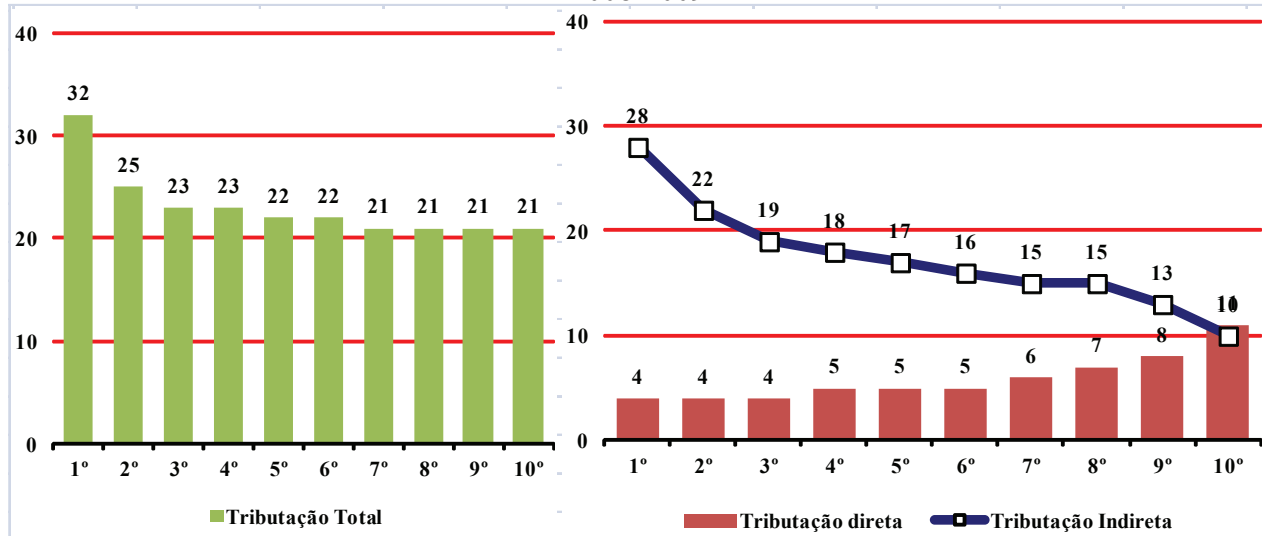

Fonte: Ipea (2011).

Em princípio, para o caso de países como o Brasil seria desejável que o sistema tributário e de gasto fossem redistributivo, mas o fato é que, no caso brasileiro, o sistema tributário mostra-se regressivo, tendo efeitos prejudiciais sobre a distribuição de renda. Os dados do Gráfico acima constataram ser a carga tributária mais pesada para os décimos de menor renda (32\% para o $1^{\circ}$ décimo da renda) e mais leve para os décimos de maior renda ( $21 \%$ para o último décimo da renda). Isso é 
explicado pelo enorme desequilíbrio entre o volume arrecadado por meio de tributos diretos (renda e patrimônio) - que tendem a ser progressivos, em comparação com o arrecadado por meio de tributos indiretos (consumo e circulação de mercadorias) - que tendem a ser regressivos. Mesmo com o ônus do tributos diretos crescendo à medida da elevação da renda, seu efeito final não é suficiente para contrabalançar o forte impacto dos tributos indiretos sobre a renda das famílias mais pobres.

$\mathrm{Na}$ comparação com outros países, a tributação no Brasil caminha em sentido inverso do adotado nos países desenvolvidos. Comparando o Brasil com países da OCDE, vê-se que em 2005 os tributos incidentes sobre bens e serviços representaram $46,1 \%$ da carga tributária brasileira, muito mais do que os $31,6 \%$ da carga tributária encontrados, em média, nos países da OCDE. Inversamente, enquanto os tributos sobre a renda aqui significaram 20,6\% da carga, entre os países da OCDE sua importância é muito maior, cerca de 35,8\% da carga. Por fim, também a tributação sobre a propriedade é subaproveitada: enquanto nos países da OCDE cerca de $5,3 \%$ da carga é originada por impostos sobre a propriedade, no Brasil essa base de incidência responde apenas por 3,8\% do total arrecadado como se vê em Brasil (2009). A excessiva carga sobre o consumo e a proporcionalmente menor carga sobre renda e patrimônio, com certeza, revelam o baixo nível de solidariedade fiscal vigente na sociedade brasileira, além da dificuldade de o Estado enfrentar o desafio de tributar de modo mais substantivo o patrimônio e as rendas oriundas de outras fontes que não o trabalho.

O sistema tributário, portanto, tal como configurado no Brasil, constitui um sério limitador à capacidade das políticas sociais em alterar a realidade social brasileira. Afinal, mesmo que as políticas sociais protejam os cidadãos mais vulneráveis, seus efeitos redistributivos serão parcialmente comprometidos pelo fato de que os beneficiários das políticas sociais são, em certa medida, também seus principais financiadores. Visto sob esse prisma, a dicotomia entre "contribuintes e não contribuintes [sic] " perde muito de seu significado, pois todos são contribuintes e mesmo os mais pobres sustentam a arrecadação tributarias devido à tributação indireta.

\section{Política social brasileira e desenvolvimento: conexão social}

A política social, conforme o que foi discutido na seção 1, é um fator fundamental do desenvolvimento e, em sua conexão social, um elemento de ampliação da justiça e coesão social. Conforme exposto nas seções anteriores, houve uma expansão da estrutura institucional, do gasto social nos últimos anos, além da extensão dos benefícios oferecidos. Consequentemente, espera-se que tenha ocorrido a alteração no quadro social brasileiro e que pode ser captada em seus indicadores. Nesse sentido, busca-se a seguir descrever e analisar alguns dos principais indicadores sociais que podem ser associados a resultados alcançados pelos programas e ações sociais no período - em especial, os que foram atingidos nas áreas de previdência, assistência social, saúde e trabalho e renda, educação, questão agrária e saneamento e habitação. 
Tabela 1

Situação social da população brasileira associada às políticas setoriais

\begin{tabular}{|c|c|c|c|}
\hline \multirow{2}{*}{$\begin{array}{l}\text { Areas de } \\
\text { Atuaç̧ấo }\end{array}$} & \multirow{2}{*}{ Indicadores } & \multicolumn{2}{|c|}{ Resultados/valores } \\
\hline & & Anos 1990 & Anos 2010 \\
\hline \multirow{5}{*}{$\begin{array}{l}\text { Previdência } \\
\text { Social }\end{array}$} & $\%$ da PIA ( 16 a 64 anos) coberta & $=$ & $64,9(2008)$ \\
\hline & $\%$ de cobertura da pop. de 65 anos ou mais & - & $93,3(2008)$ \\
\hline & $\%$ de beneficios menores que 1 s.m. & - & $2,0(2007)$ \\
\hline & $\%$ de beneficios maiores que 1 s.m. & $=$ & $42,0(2007)$ \\
\hline & $\begin{array}{l}\% \text { de domicilios com individuos com mais de } 60 \\
\text { anos que recebem aposentadoria ou pensão }\end{array}$ & $72,8(1995)$ & $73(2007)$ \\
\hline \multirow{2}{*}{$\begin{array}{l}\text { Assistëncia } \\
\text { Social }\end{array}$} & $\begin{array}{l}\text { \% da população vivendo com menos de RS } 131 \text { per } \\
\text { capita (linha superior de elegibilidade para o Bolsa } \\
\text { Familia } \mathrm{cm} 2009 \text { ) }\end{array}$ & $27,3(1995)$ & $13,7(2009)$ \\
\hline & $\begin{array}{l}\text { \% da populaçảo vivendo com menos de RS } 66 \text { per } \\
\text { capita (linha inferior de elegibilidade para o Bolsa } \\
\text { Familia em 2009) }\end{array}$ & $10,7(1995)$ & $4,8(2009)$ \\
\hline \multirow{3}{*}{ Saúde } & $\begin{array}{l}\text { Taxa de Mortalidade Infantil (por mil Nascidos } \\
\text { Vivos) }\end{array}$ & $47,1(1990)$ & $19,0(2008)$ \\
\hline & Taxa de Mortalidade na Infïncia & $53,7(1990)$ & $22,8(2008)$ \\
\hline & Esperança de Vida ao Nascer (anos) & $68,5(1995)$ & $72,1(2007)$ \\
\hline \multirow{2}{*}{$\begin{array}{l}\text { Trabalho e } \\
\text { Renda } \\
\text { (Proteçâo) }\end{array}$} & Taxa de Cobertura Efetiva do seguro-desemprego & $65,9(1995)$ & $62,9(2007)$ \\
\hline & Taxa de Reposição do seguro-desemprego & $50,9(1995)$ & $68,3(2007)$ \\
\hline \multirow{3}{*}{$\begin{array}{l}\text { Trabalho e } \\
\text { Renda } \\
\text { (Promoçāo) }\end{array}$} & Taxa de aderência da intermediaçào & $39,2(1995)$ & $47,5(2007)$ \\
\hline & Taxa de admissão da intermediação & $1,5(1995)$ & $6,8(2007)$ \\
\hline & Taxa de frequẻncia à escola ( 0 a 3 anos) & $7.5(1995)$ & $18.2(2009)$ \\
\hline \multirow{6}{*}{ Educação } & Taxa de frequència à escola ( 4 a 6 anos) & $53,4(1995)$ & $81,3(2009)$ \\
\hline & Taxa de frequência ả escola ( 7 a 14 anos) & $86,6(1992)$ & $98,0(2009)$ \\
\hline & Taxa de frequência à escola ( 15 a 17 anos) & $59.7(1992)$ & $85,2(2009)$ \\
\hline & Taxa de frequência à escola ( 18 a 24 anos) & $22,6(1992)$ & $30,3(2009)$ \\
\hline & Taxa de analfabetismo (15 anos ou mais) & $17,2(1992)$ & $9,7(2009)$ \\
\hline & Número médio de anos de estudos ( 15 anos ou mais) & $5,2(1992)$ & $7,5(2009)$ \\
\hline $\begin{array}{l}\text { Questào } \\
\text { Agrária }\end{array}$ & $\begin{array}{l}\text { Concentração Fundiária - indice de Gini para } \\
\text { propriedade da terra }\end{array}$ & $0,838(1998)$ & $0,816(2003)$ \\
\hline \multirow{3}{*}{$\begin{array}{l}\text { Saneamento } \\
\text { c Habitaçāo }\end{array}$} & $\begin{array}{l}\% \text { Abastecimento de Água (urbano) } \\
\% \text { Esgoto Sanitário (urbano) } \\
\% \text { Coleta de Lixo (urbano) }\end{array}$ & $\begin{array}{r}82,3(1992) \\
66,1(1992) \\
79,8(1992)\end{array}$ & $\begin{array}{r}91,6(2008) \\
81(2007) \\
97,6(2007)\end{array}$ \\
\hline & $\begin{array}{l}\% \text { Domicilios urbanos com condiçōes de moradia } \\
\text { adequada }\end{array}$ & $50,7(1992)$ & $65,7(2008)$ \\
\hline & Déficit Habitacional total (Habitaçōes) & n.d. & $\begin{array}{r}5,7 \text { milhões } \\
(2008)\end{array}$ \\
\hline \multirow{6}{*}{$\begin{array}{l}\text { Renda e } \\
\text { Desigualdade }\end{array}$} & $\begin{array}{l}\text { Renda domiciliar per capita média em USS PPC por } \\
\text { dia }\end{array}$ & $5,5(1990)$ & $12,1(2008)$ \\
\hline & Desigualdade de renda - Gini & $0.601(1990)$ & $0.538(2009)$ \\
\hline & $\begin{array}{l}\% \text { da populaçãa vivendo com menos de USS PPC } \\
1,25 \text { por dia (situação de extrema pobreza) - critério } \\
\text { ONU/ODM - }\end{array}$ & $25,6(1990)$ & $4,8(2008)$ \\
\hline & $\begin{array}{l}\text { Populaçåo total vivendo com menos de USS PPC } \\
1,25 \text { por dia (situaçäo de extrema pobreza) - critério } \\
\text { ONU/ODM }\end{array}$ & $\begin{array}{r}36.2 \text { milhöes } \\
(1990)\end{array}$ & $\begin{array}{l}8,9 \text { milhöes } \\
\text { (2008) }\end{array}$ \\
\hline & $\%$ da renda nacional detida pelos $20 \%$ mais pobres & $2,2(1990)$ & $3,1(2008)$ \\
\hline & Salärio minimo em USS PPC por dia & $4,0(1990)$ & $8,4(2008)$ \\
\hline
\end{tabular}

Fonte: Ipea (2010a; 2010c).

No que diz respeito à Proteção Social, a área da Previdência Social apresenta duas situações distintas. Primeiro, diz respeito à cobertura da política com respeito à População em Idade Ativa (PIA) que é de apenas 65\%. Esse valor indica que um amplo conjunto de brasileiros ainda não está coberto pela política previdenciária, 
tornando-se necessário e urgente a elaboração e implementação de ações com vista à inclusão de tais brasileiros no sistema. A segunda situação diz respeito à população inativa com alto grau de cobertura e observa que cerca de $93,3 \%$ da população com mais de 65 anos está coberta pelo sistema. Assim, demostra a efetividade do sistema para cobrir as necessidades desses brasileiros.

Em função do último resultado a citada política permite existir certo padrão distributivo, principalmente, devido à oferta de benefícios para os trabalhadores em regime de economia familiar - benefícios com perfil não contributivo e com valor em torno do salário mínimo. Quem, então, se beneficiou foi um amplo conjunto de trabalhadores, que se localizava na base da pirâmide social (trabalhadores sem inserção no mercado formal, pequenos produtores agropecuários e pescadores artesanais os quais trabalham em família e não contam com empregados no desenvolvimento de suas atividades). Como resultado, caso fosse retirada as rendas da previdência, os números da indigência e pobreza (renda domiciliar per capita inferior a $1 \frac{1}{4}$ de salário mínimo e de 1/2 salário minimo), em 2007, seriam maiores em 17,6 milhões e 20,6 milhões. Da mesma maneira, por conta do referido pagamento, a desigualdade de renda no país (medida pelo índice de Gini) diminuiu 7,4\%, evidenciando o caráter distributivo da política previdenciária.

Na assistência social, a ampliação e a diversificação dos benefícios trouxe resultados expressivos à população caracterizada por indicadores de vulnerabilidade. A disponibilização do BPC à população idosa e portadora de deficiência vivendo em extrema pobreza, cujos valores são corrigidos pelo SM, bem como a oferta de um conjunto de transferências diretas de renda à população em situação de pobreza, principalmente o Programa Bolsa Família, ajudaram em uma diminuição da taxa de extrema pobreza e de pobreza ao longo dos últimos anos, como pode ser constatado no Gráfico 4.

Gráfico 4

Proporção da população em situação de pobreza e extrema pobreza - 1995-2009

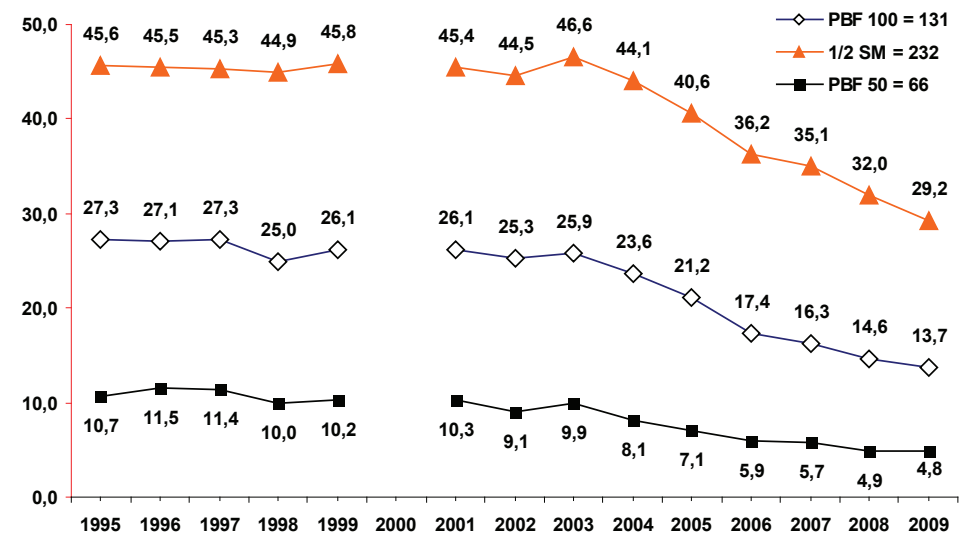

Fonte: Ipea (2010c). 
Pelo critério do PBF, a pobreza (renda domiciliar per capita de até R\$131) teve reduzida sua incidência de 27,3\% da população no ano de 1994 para 13,7\% no ano de 2009. Já, a extrema pobreza (renda domiciliar per capita de até R\$ 66) reduziu-se de 10,7\% da população brasileira em 1994 para 4,5\% em 2009, ou seja, diminuiu mais que a metade. É verdade que não se pode isolar precisamente os efeitos da política assistencial de outros efeitos (como os da expansão e da diversificação da política previdenciária e trabalhista desde o início dos anos 90 , bem como da melhora do funcionamento do mercado de trabalho brasileiro após o início dos anos 2000). De toda forma, os números a respeito da queda da extrema pobreza e da pobreza consistem em indícios da distributividade da política assistencial estruturada nos anos recentes ${ }^{13}$.

A situação social da população na área de Saúde pode ser analisada pelos avanços de um dos principais indicadores que é a taxa de mortalidade infantil. Este indicador reduziu-se de 47,1 óbitos por mil nascidos vivos em 1990 para 19,0 em 2008, se considerado o conjunto do Brasil. Movimento semelhante ocorreu com a taxa de mortalidade na infância que diminuiu de 53,7 óbitos por mil nascidos vivos em 1990 para 22,8 no ano de 2008. De qualquer modo, a ampliação do acesso a bens e serviços de saúde dos últimos vinte anos, com uma marcada perspectiva preventiva, resultou não só em uma alteração do padrão de mortalidade, mas em uma melhoria concreta e efetiva das condições de saúde da população brasileira. Isso se refletiu, por exemplo, na extensão da esperança de vida ao nascer que passou de 68,5 anos em 1995 para 72,1 anos em 2007. Tais indicadores mostram que a política protegeu uma parcela mais extensa da população (não só aquela inserida formalmente no mercado de trabalho), bem como ofereceu a proteção contra um leque mais diversificado de riscos e agravos (inclusive com um foco preventivo de atuação).

Ainda na área da proteção social, têm-se as ações da área de Trabalho e Renda, principalmente, aquela voltada ao seguro-desemprego que aumentou sua concessão em $17 \%$ de 1995 a 2007 . Na verdade, contudo, mostrou uma estabilidade em sua taxa de cobertura (número de trabalhadores protegidos/número de trabalhadores demitidos sem justa-causa do setor formal) em torno de $64 \%$. Não obstante, a taxa de reposição desse benefício (valor médio do seguro-desemprego recebido pelos trabalhadores / valor médio do último salário dos trabalhadores demitidos) apresentou uma tendência de melhora, passando de 51,0\% em 1995 para 68,3\% em 2007.

No campo da Promoção Social, a ação pública na área de trabalho ampliouse e diversificou-se nos últimos anos. No que se refere à procura por um novo emprego/nova ocupação por parte dos trabalhadores, a intermediação realizada pelo Sine mostrou alguns sinais positivos, como o da taxa de aderência da intermediação (número de trabalhadores colocados por meio do Sine/número de vagas captadas

(13) Para mais detalhes, ver Ipea (2010c). 
pelo Sine) que passou de 39,2\% em 1995 para 47,5\% em 2007, bem como o da taxa de admissão da intermediação (número de trabalhadores colocados por meio do Sine / número de trabalhadores admitidos segundo o Caged), sendo de 1,5\% em 1995 para $6,8 \%$ em 2007.

Na área de Educação, houve uma ampliação e diversificação dos bens e serviços, principalmente para a população infanto-juvenil, o que permitiu um importante movimento de inclusão de crianças, adolescentes e jovens nas escolas e universidades brasileiras. Tal fenômeno pode ser observado na análise de indicadores como a taxa de frequência da população entre 4 e 6 anos de idade (pré-escola) que se expandiu de 26,9\% em 1988 para 77,6\% em 2007. Quanto à taxa de frequência do grupo entre 7 e 14 anos de idade (ensino fundamental), as porcentagens aumentaram de $84,1 \%$ para $97,6 \%$ nesse lapso de tempo.

Apesar dos avanços, a proporção de analfabetos na população com 15 anos ou mais permanece em patamar bastante elevado, principalmente por conta das gerações mais idosas. Apresentou, todavia, tendência de redução, progredindo de 17,2\%, da população com 15 anos ou mais em 1992 para 9,7\% em 2009. Um indicador que complementa esse cenário da situação educacional é o número médio de anos de estudo para o grupo com 15 anos ou mais que cresceu no período em análise, passando de 5,1 anos para 7,3 anos. É verdade que, em tal cenário, os anos de estudo da população não contemplam sequer o que era considerado obrigatório pela Constituição (ciclo fundamental completo -8 anos de estudo). Não obstante, eles revelam algum grau de sucesso das iniciativas de ampliação e diversificação dos serviços educacionais no Brasil - em especial, no que se refere à população infantojuvenil que passou a contar com um acesso bem mais significativo à escola.

No que se refere à cobertura dos serviços de saneamento básico no Brasil, a proporção da população em áreas urbanas servida por água de rede geral com canalização interna, em 2008, girava em torno de 91,6\%, um aumento de quase 10 p.p. em relação a 1992. A cobertura de serviços de esgotamento sanitário, mesmo tendo aumentado significativamente, ainda é muito inferior à cobertura de água, embora $80,5 \%$ da população urbana já conta com esgotamento sanitário por rede geral ou fossa séptica, um crescimento de 14 p.p. desde 1992. As desigualdades no acesso aos serviços de saneamento básico entre os grupos socioeconômicos, as áreas urbanas e rurais e as grandes regiões, mesmo tendo diminuído, ainda continuam bastante significativas.

Houve, também, uma melhora substancial no que se refere às condições habitacionais. A proporção de pessoas residentes em domicílios urbanos com condições de moradia adequadas passou de 50,7\% em 1992 para 65,7\% em 2008. Mesmo assim, 54,5 milhões de pessoas moradoras nas cidades ainda sofrem de algum tipo de carência habitacional. 
No que diz respeito à desigualdade na primeira década do século 21 , o Brasil apresenta uma marcha distinta da verificada no período anterior, combinando positivamente a redução do grau de desigualdade na distribuição pessoal da renda pessoal (ver Gráfico 5, a seguir) com a elevação da participação dos rendimentos do trabalho na renda nacional. Isso porque houve uma mudança de trajetória e, nas últimas décadas do século 20, havia uma trajetória de queda da participação do rendimento do trabalho na renda nacional, menor ritmo de expansão econômica e desajustes nas finanças públicas. No biênio 2008/09, por exemplo, o peso do trabalho na renda nacional aumentou 9,5\% em relação aos anos 1999/2000, pois passou de $40 \%$ para $43,6 \%$, considerando-se como rendimento do trabalho a renda dos ocupados mais as transferências de renda, conforme Ipea (2010b).

Gráfico 5

Evolução da desigualdade pessoal da renda - 1990-2009

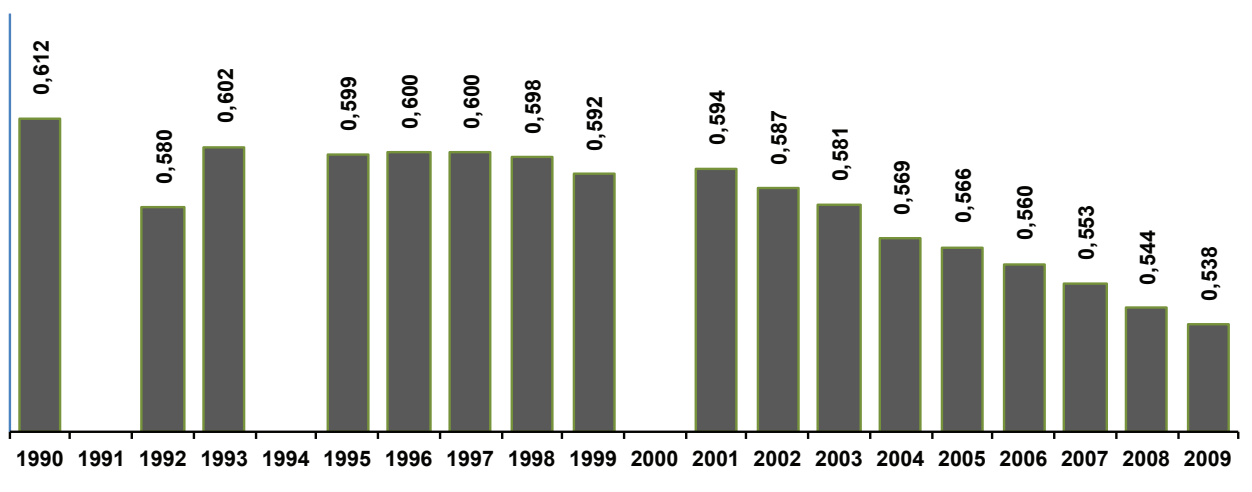

Fonte: IPEA/Ipeadata.

Em síntese, o Brasil encontra-se em um momento especial do contexto geral de enfrentamento da desigualdade de renda (pessoal e funcional), com movimento favorável aos portadores de rendimentos do trabalho, sobretudo àqueles com menor remuneração. Observa-se que, desde a estabilidade monetária, as menores remunerações apresentam crescimento real. O evento da crise internacional, em 2008, estimulou a adoção de importantes medidas de defesa da produção e do emprego nacional, permitindo, assim, evitar a inflexão na trajetória de queda no grau de desigualdade na distribuição funcional e pessoal da renda. Tanto foi que o rendimento do trabalho continuou a recuperar sua participação relativa na renda nacional, enquanto o índice de Gini seguiu a tendência de queda, como mostra o Gráfico 5.

Em linhas gerais, os dados e indicadores apresentados apontam para uma melhoria da situação social da população no período atual nos diversos sentidos apresentados. Esses resultados, em grande parte, são resultantes da ampliação da 
política social que, mediante o maior volume na utilização de recursos humanos, físícos e financeiros por parte do estado, possibilitou ampliar a justiça social no Brasil mediante a maior transferência de rendas, maior oferta de bens e serviços sociais, o que resultou em uma diversificação e em uma melhoria da proteção social/ geração de oportunidades para a população brasileira como os diversos indicadores reveleram.

\section{Política social e desenvolvimento: conexão econômica}

Tratando-se da conexão econômica, a Política Social e o seu correspondente gasto público é um dos componentes da demanda agregada e elemento importante para promover o crescimento econômico e uma melhor distribuição de renda. Isso ocorre porque a maioria dos gastos sociais, conforme apresentado na Figura 2, são relativos à garantia de renda mediante as transferências de rendas a pessoas/famílias (por exemplo, em 2010, foram distribuídos cerca de 54 milhões de beneficios mês). A compra de bens no mercado (livros, computadores, alimentos etc.) e a remuneração de servidores (auxiliares, técnicos, professores, médicos, engenheiros etc.) foram cerca de 4,7 milhões de empregados diretos em 2010 que, para manterem a si e a família, realizam seus gastos no mercado interno brasileiro, em sua maioria.

O processo de gasto fortalece o circuito de multiplicação de renda, pois tais extratos tendem a consumir menos importados e poupar menos, o que implica em maior propensão a consumir, em geral, com mais produtos nacionais, em particular, o que propicia maiores vendas, mais produção e mais emprego gerado no país. O gasto com às políticas sociais, portanto, tem reflexo de caráter estritamente econômico em dois sentidos: i) em termos de seu multiplicador para o crescimento do PIB e da renda das famílias; ii) também na distribuição da renda, que são apresentados a serguir, tomando como base cálculos efetuados em Ipea (2010e).

\subsection{Efeito crescimento sobre o PIB e a renda das famílias}

Para captar os efeitos da política social em sua conexão com a economia, buscou-se medir o crescimento econômico (sobre o PIB) e da renda das famílias para choques de gastos em alguns tipos de despesas sociais mediante a reconstrução de seu ciclo econômico, utilizando uma Matriz de Contabilidade Social para o Brasil, para o ano de 2006. Após a simulação de gastos, o ciclo econômico revela a existência de um multiplicador do PIB de aproximadamente 1,37, decorrente de um aumento nas variáveis exógenas da demanda agregada provenientes do gasto social. Isso significa que, a cada novo $\mathrm{R} \$ 1,00$ gasto pelo governo na área social, podem ser gerados $\mathrm{R} \$ 1,37$ de PIB, quando se completa o ciclo.

Realizando o ciclo econômico de forma distinta para cada área social, dão os resultados que são apresentados no Gráfico 6. Esses dados mostram que algumas 
áreas possuem multiplicadores do PIB bem superiores às outras. A área de educação e de saúde, por exemplo, têm os maiores multiplicadores e os gastos com o RPPS são aqueles de pior multiplicador, ou seja, gastar em algumas áreas sociais é melhor para crescimento da economia que em outras.

Quando se compara os resultados das simulações para os gastos nas áreas sociais com os resultados de gastos de outros setores tais como: construção civil, exportação de commodities e juros da dívida, observa-se que os gastos de educação e saúde continuam tendo melhores multiplicadores e o PBF e o BPC aproximamse do multiplicador das exportação de commodities. Em contrapartida, esses dados também revelam como os gastos com juros da dívida são ruins ao crescimento, pois têm o pior multiplicador.

Significa que os resultados demonstram como os principais gastos na área social são importantes para dinâmica da economia nacional, principalmente, por seus efeitos sobre o mercado interno.

Gráfico 6

Efeito multiplicadordos gastos das áreas sociais e outras áreas selecionadas no PIB - 2006

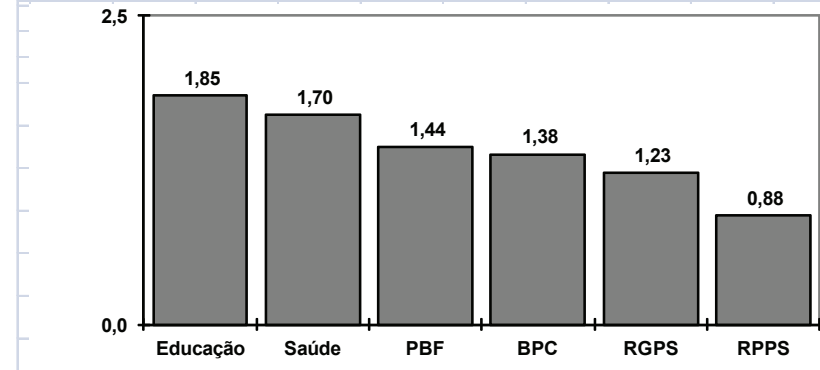

口Áreas sociais

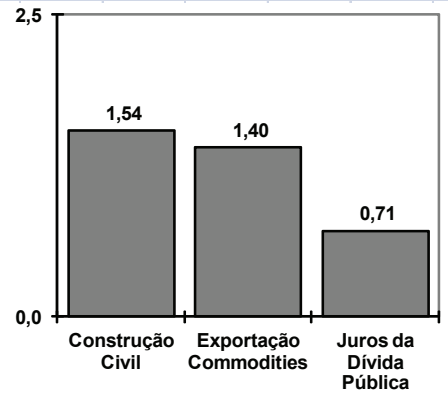

口Outras

Fonte: Ipea (2010e). Elaboração própria.

Quanto ao que ocorre com a renda das famílias, as simulações demostraram que um incremento de $1 \%$ do PIB nos programas e políticas sociais detalhados eleva a renda das famílias em 1,85\%, em média - sabe-se que a renda das famílias constituiu importante parcela do PIB brasileiro. Os resultados para renda das famílias a cada área social, apresentados no Gráfico 7, mostram resultados bem distintos dos anteriores. Agora, as transferências de renda são bem superiores que os demais, por exemplo os gastos do PBF e do BPC são bem superiores em termos de importância para a renda da família do que os demais gastos sociais. 
Gráfico 7

Efeito multiplicador dos gastos em áreas socais e outras áreas selecionadas na renda das famílias 2006

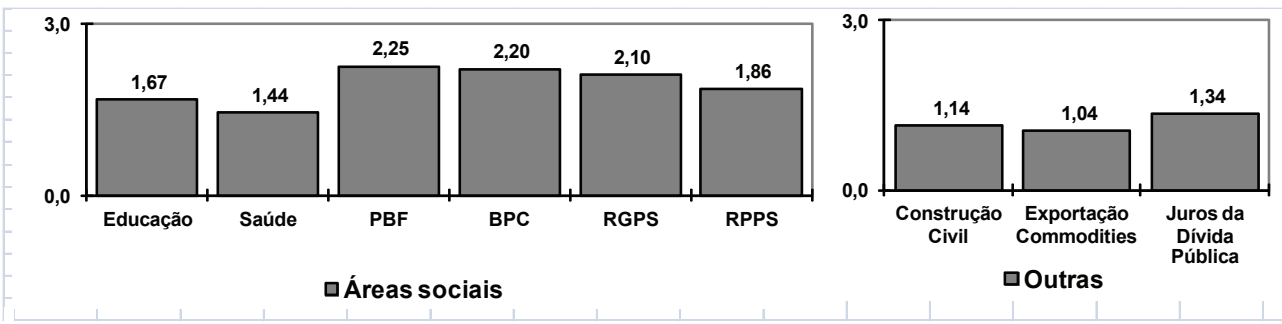

Fonte: IPEA (2010e). Elaboração própria.

Quando se compara os resultados das simulações para os gastos nas áreas sociais com os resultados de gastos de outros setores tais como: construção civil, exportação de commodities e juros da dívida, observa-se que esses gastos têm menor importância para renda das famílias do que qualquer gasto das áreas sociais.

Os resultados apresentados demonstram que os principais gastos na área social são extremamente importantes para a renda das famílias.

\subsection{Efeito distribuição}

Reconstruídas as novas matrizes de contabilidade social, resultantes dos diversos incrementos nos gastos que foram simulados, pode-se aferir, não só o multiplicador médio da renda das famílias, mas também o multiplicador da renda de cada um dos grupos de famílias investigadas (mesclando o local de residência e a escolaridade do chefe). Assim, é possível sabermos a variação na distribuição de renda ocorrida a partir do incremento de cada tipo de gasto.

O Gráfico 8 mostra os efeitos distributivos do gasto social, com base em variações do índice de Gini “estilizado". No caso da saúde e educação, incorporandose o consumo desses serviços à renda familiar ${ }^{14}$, ambos são progressivos: i) o choque de $1 \%$ do PIB no gasto com saúde enseja uma diminuição de $1,5 \%$ no índice de Gini; ii) no caso da educação, a queda é um pouco menor, 1,09\%, devido à educação superior, em que é maior a presença de famílias de maior renda. As exportações de commodities, por seu turno, têm efeitos basicamente neutros, ou seja, geram crescimento, porém corroborando os altos níveis de desigualdade de renda em que vivemos.

(14) É preciso fazer a apropriação do gasto do governo à renda das famílias beneficiárias desses gastos porque os mesmos se comportam como uma transferência às famílias dedicadas ao consumo de educação e saúde. Afinal, o consumo do governo não é propriamente dele, mas das famílilas que se beneficiam de tal produção/ provisão pública. Se não não for feito, a comparação dos efeitos dos agregados estudados sobre a distribuição fica prejudicada, sobreestimando os efeitos das transferênciasdiretas de renda e subestimando o impacto do acesso a bens e serviços sociais. 
Gráfico 8

Variação percentual do Gini em relação ao índice inicial, após as simulações - 2006

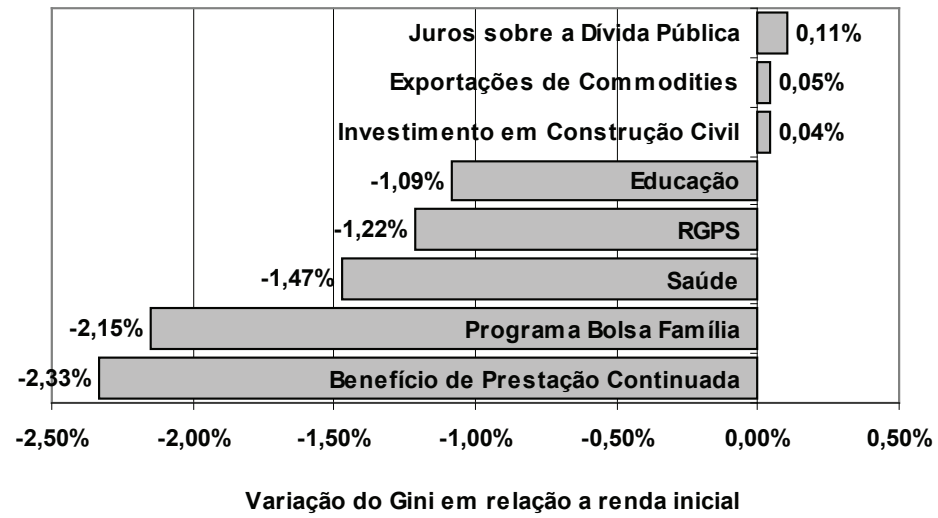

Fonte: Ipea (2010e). Elaboração própria.

Entre as transferências, gastos incrementais no BPC e no PBF são claramente os que mais contribuem para a queda da desigualdade $(-2,33 \%$ e $-2,15 \%$ no índice de Gini estilizado, respectivamente). A previdência social tem efeitos benéficos sobre a desigualdade, reduzindo o índice em 1,2\%.

Nesse ponto, caberia perguntar: são significativas as contribuições de cada política para a queda da desigualdade? Parece que sim. Para que se possa ter um parâmetro de comparação, a melhora recente da desigualdade brasileira entre 2003 e 2008, medida pelo gini, ocorreu com velocidade média de $-1,3 \%$ ao ano, ou seja, alguns gastos sociais mais progressivos, se expandidos, ainda podem contribuir substancialmente para a desconcentração de renda no Brasil.

\subsection{Efeitos combinados - crescimento e distribuição}

Em suma, veem-se resultados positivos acerca do papel virtuoso do gasto em bens e serviços educacional, saúde, mais especificamente, das transferências de renda direcionadas para os mais pobres. O Gráfico 9 mostra o cruzamento dos dados já comentados, isto é, no eixo vertical, há a variação percentual do PIB provocada pelo choque de $1 \%$ em diversas áreas sociais e não sociais e no eixo horizontal, temse a variação percentual do índice de Gini “estilizado" decorrente do mesmo choque. 
Gráfico 9

Efeitos combinados de gastos das áreas sociais e outras áreas selecionadas sobre o crescimento econômico e a distribuição da renda - 2006

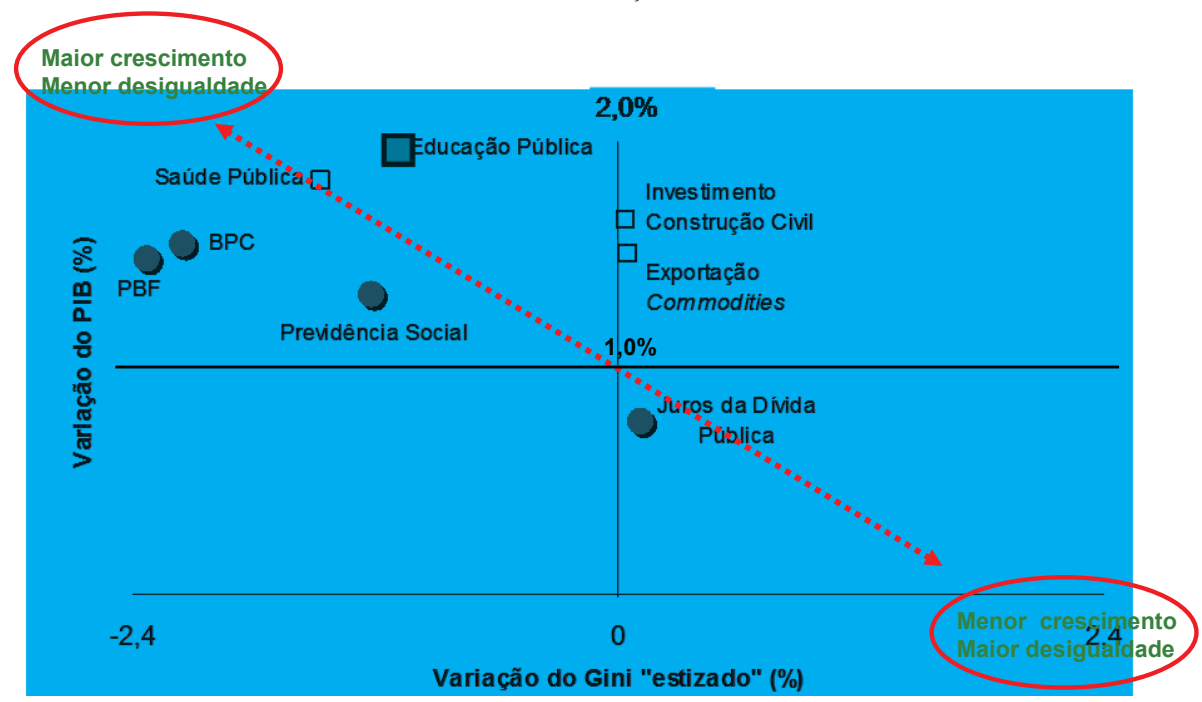

Fonte: Ipea (2010). Elaboração própria.

Se for assumido que uma das metas de desenvolvimento nacional é conseguir unir maior crescimento econômico e menor desigualdade de renda, então todos os gastos do quadrante à esquerda contribuem para esse ideal. Observa-se que não há, em absoluto, um trade-off entre crescimento e equidade, muito pelo contrário, pois o incremento dos gastos em saúde e educação públicas gera desdobramentos muito positivos tanto em termos de crescimento quanto de distribuição de renda. Já, o incremento no gasto do $\mathrm{PBF}$ e no BPC, por exemplo, provoca, ao mesmo tempo, uma grande variação positiva do PIB e a maior queda na desigualdade. O Regime Geral da Previdência Social RGPS fica um pouco atrás em ambos os quesitos, mas também desempenha um papel positivo.

O aumento do investimento no setor de construção civil e as exportações de commodities agrícolas e extrativas promovem crescimento do PIB, mas reproduzem o nível de desigualdade. Por sua vez, um incremento no pagamento de juros contribui pouco para o crescimento e aumenta a concentração de renda.

Tais resultados são importantes para demonstrar que o gasto com as políticas sociais ao cumprir seu propósito central de proteção e promoção social é, ao mesmo tempo, um elemento muito importante para dinâmica da economia nacional, principal daquele voltado para o mercado interno e diminuição da desigualdade. 


\section{Considerações finais}

As informações anteriores demonstraram a complexidade da Política Social estruturado no Brasil nos últimos anos. Assim, também revelou que não foram poucos os avanços registrados na situação social da população brasileira nos últimos anos e, em alguma medida, esses avanços estão associados às políticas sociais as quais exigiram um maior esforço da economia e da sociedade em termos de recursos para financiamento de programas e ações.

As políticas sociais puderam contar com a ampliação de recursos físicos, financeiros, humanos e institucionais, possibilitando a estruturação de um amplo e diversificado conjunto de mecanismos de proteção e promoção social fundamentais para ampliar a justiça e coesão social, com melhorias substantivas nas condições básicas de vida da população. Assim, a política social transformou-se em um poderoso instrumento por meio do qual a economia nacional não apenas efetuou transferências de renda e prestações de bens e serviços ao conjunto da sociedade, mas, simultaneamente, gerou um canal de ampliação da demanda agregada, com capacidade de criar um amplo mercado interno de consumo.

Dinamizou, portanto, a produção, estimulou o emprego, multiplicando a renda e reduziu a pobreza e extrema pobreza, diminuindo a desigualdade.

Os resultados apresentados permitem afirmar que a política social tem papel estratégico como alavancadora do desenvolvimento nacional, mediante seus resultados na ampliação da justiça e coesão social, crescimento e distribuição de renda, reafirmando-se como indispensável e estratégica, não apenas para enfrentar situações conjunturais adversas, como também para criar os alicerces da construção de uma nação econômica e socialmente mais forte.

\section{Referências bibliográficas}

ALCOCK, P. Social policy in Britain: themes and issues. London: Macmillan Press Ltd., 1996.

AMITRANO, C. Regime de crescimento, restrição externa e financeirização: uma proposta de concilização. Brasilia, Ipea, 2011. (Texto para Discussão, n. 1612).

ARRETCHE, M.. Emergência e desenvolvimento do Welfare State: teorias explicativas. BIB, n. 39, p. 3-40, 1995.

BALDWIN, P. The politics of social solidarity: class bases of the European Welfare State 1875-1975. Cambridge University Press, 1990.

BRASIL, Presidência da República, Observatório da Equidade. Indicadores de equidade do Sistema Tributário Nacional. Brasília: Presidência da República, Observatório da Equidade, 2009. 
BOBBIO, N. A grande dicotomia público-privado. In: BOBBIO, N. Estado, governo e sociedade: para uma teoria geral da política. São Paulo: Paz e Terra. 1987.

BOSCHETTI, I.; BEHRING, E. Política social: fundamentos e história. São Paulo: Cortez, 2006.

BRUNO, M. et al. Finance-led growth regime no Brasil: estatuto teórico, evidências e consequências macroeconômicas. Brasília: Ipea, dez, 2009. (Texto para Discussão, n. 1455).

CASTEL, R. A metaformose da questão social. Rio de Janeiro: Vozes, 1998.

CASTRO, J. A. Política social: alguns aspectos relevantes para discussão. In: CONCEPÇÃO e gestão da proteção social não contributiva no Brasil. Brasília: Ministério do Desenvolvimento Social, jun. 2009. dez. 2008.

et al. Política Social: vinte anos da constituição federal de 1988. Brasília: Ipea,

COMISSIÓN ECONÓMICA PARA A AMÉRICA LATINA Y EL CARIBE (Cepal). Panorama social de America Latina, 2007. Santiago, Chile, 2008.

- Cohesión social: inclusión y sentido de pertenencia em America Latina y el Caribe. Santiago, Chile, 2007.

. Equidad, dessarrollo y cidadanía. Santiago, Chile, 2000.

. Educación y connocimiento: eje de la transformación productiva com equidad. Santiago, Chile, 1992.

CHANG, H. Chutando a escada: a estratégia do desenvolvimento em perspectiva histórica. São Paulo: Editora Unesp. 2004.

COIMBRA, M. Abordagens teóricas ao estudo das políticas sociais. In: POLÍTICA social e combate a pobreza. Rio de Janeiro: Ed. Zahar, 1987.

DELGADO, G.; THEODORO, M. Desenvolvimento e política Social. In: JACCOUD, L. Questão social e políticas sociais no Brasil Contemporâneo. Brasília: Ipea, 2005.

DRAIBE, S. Rumos e metamorfoses: estado e industrialização no Brasil 1930/1960. Rio de Janeiro: Paz e Terra, 1985.

; AURELIANO, L. A especificidade do Welfare State Brasileiro. In: A POLÍTICA social em tempo de crise, Economia e Desenvolvimento 3, Brasília: MPAS/Cepal, 1989.

; HENRIQUE, W. "Welfare state", crise e gestão da crise: um balanço da literatura internacional. Revista Brasileira de Ciências Sociais, Anpoccs, n. 6, 1988.

ESPINA, Á. Modernización, estadios de desarrollo económico y regimenes de bienestar em América Latina. Madrid: Fundación Carolina, set. 2008.

ESPING-ANDERSEN, G. As três economias do Welfare State. Lua Nova, n. 24. p. 85-115. 1991. 
ESPING-ANDERSEN, G. Welfare states in transition. National adaptations in global economies. London: Sage, 1996.

EVANS, P. Constructing the 21 st century developmental state: potentialities and pitfalls. In: EDIGHEJI , Omano (Ed,). Constructing a democratic developmental state in South Africa potentials and challenges. Capetown, South Africa: HSRC Press, 2010.

FAGNANI, E. Política social e pactos conservadores no Brasil: 1964/92. Economia e Sociedade, Campinas, n. 8, p. 183-238, 1997.

- Ajuste econômico e financiamento da política social brasileira: notas sobre o período 1993/98. Economia e Sociedade, Campinas, n. 13, dez. 1999.

FERRERA, M. The 'Southern model' of welfare in social Europe. Journal of European Social Policy, v. 6, n. 1, p. 17-37, 1996.

FLEURY, S. A seguridade social e os dilemas da inclusão social. RAP, Rio de Janeiro, v. 39, n. 3, p. 449-469, maio/jun. 2005.

FLORA, P. (Org.). Growth to limits: the western European Welfare States since word war II. New York: The Gruyter, 1986.

; HEIDENHEIMER (Org.). The development of the Welfare State in Europe and America. London: New Brunswick, 1981.

FURTADO, C. Desenvolvimento e subdesenvolvimento. Rio de Janeiro: Editora Fundo de Cultura, 1961.

. O subdesenvolvimento revisitado. Economia e Sociedade, Campinas, n. 1, 1992.

. Raizes do subdesenvolvimento. Rio de Janeiro: Civilização brasileira, 2011.

INSTITUTO DE PESQUISA ECONÔMICA APLICADA (Ipea). Boletim de Políticas Sociais - Acompanhamento e Análise, Brasília, n. 13, mar. 2007.

. Situação social brasileira 2007. Brasília, nov. 2008.

. Boletim de Politicas Sociais - Acompanhamento e Análise, Brasília, n. 17, fev.

2010a.

Distribuição funcional da renda pré e pós crise internacional no Brasil. Comunicado do IPEA, Brasília, n. 47, maio 2010b.

PNAD 2009 - Primeiras análises: distribuição de renda entre 1995 e 2009. Comunicado do Ipea, Brasília, n. 63, out. 2010c.

PNAD 2009 - Primeiras análises: situação da educação brasileira - avanços e problemas. Comunicado do Ipea, Brasília, n. 66, nov. $2010 \mathrm{~d}$.

. Perspectiva da política social no Brasil. Brasília, dez. 2010e. Livro 8.

. O regime de crescimento econômico brasileiro: uma apreciação sobre o período 1995-2009. Brasil em Desenvolvimento, Brasilia, $2010 \mathrm{f}$. 
INSTITUTO DE PESQUISA ECONÔMICA APLICADA (Ipea). Equidade fiscal no Brasil: impactos distributivos da tributação e do gasto Social. Comunicado do IPEA, Brasília, n. 92, maio 2011.

JACCOUD, L. (Org.). Questão social e políticas sociais no Brasil comtemporâneo. Brasília: Ipea, 2005.

GOUGH, I. Welfare state in East Asia and Europe. Paper presented at the session Toward the new social policy agenda. Annual World Bank Conference on Development Economics Europe. Paris 27 Jun. 2000.

KING, D. O Estado e as estruturas sociais de bem-estar em democracias industriais avançadas. Novos Estudos Cebrap, n. 22, 1988.

LESSA, C. A estratégia de desenvolvimento: sonho e fracasso, Brasília: Funcep, 1988.

MARSHAlL, T. H. Política social. São Paulo: Zahar Ed., 1967.

MISHRA, R. Social welfare: national and international dimensions. International Social Work. Sage Journals, London, v. 30, n. 2, Apr. 1987.

POCHMANN, M. (Org.). Desenvolvimento, trabalho e solidariedade. Novos caminhos para a inclusão social. São Paulo: Cortez/Editora Fundação Perseu Abramo, 2002.

POLANYI, K. A grande transformação. Rio de Janeiro: Ed. Campus, 1980.

PRZEWORSKI, A. Capitalismo e social democracia. São Paulo: Cia das Letras, 1989.

RAWLS, J. Justiça como equidade. São Paulo: Martins Fontes. 2003.

RAWLS, J. Justiça como equidade - uma concepção política não metafísica. Lua Nova, São Paulo, n. 25, 1992.

ROSANVALLON, P. A nova questão social. Brasília: Instituto Teotônio Vilela, 1998.

SANTOS, W. G. Cidadania e justiça. A política social na ordem brasileira. 2. ed. Rio de Janeiro: Ed. Campus, 1987.

SEN, A. A ideia de justiça. São Paulo: Companhia das Letras, 2011.

. Desigualdade reexaminada. Rio de Janeiro: Record. 2001. . Desenvolvimento como liberdade. São Paulo: Cia. das Letras. 2000.

SCKOCPOL, T. Social policy in the United States. New Jersey: Priceton University Press, 1994.

SPOSATI, A. Modelo brasileiro de proteção social não contributiva: concepções fundantes. In: CONCEPÇÃO e gestão da proteção social não contributiva no Brasil. Brasília: Unesco/ Mds, 2009.

TAYLOR-GOOBY, P. Equality, rights and social justice. In: ALCOCK, P.; ANGUS, E.; MAY, M. (Edit.). The students companion to social policy. London: Blackwell Pub. 1998. 
TAVARES, M. C. Acumulação de capital e industrialização no Brasil. Campinas: IE/ Unicamp. 1998a. (Coleção 30 anos de Economia).

Ciclo e crise (O movimento recente da industrialização brasileira). Campinas: IE/ Unicamp. 1998b. (Coleção 30 anos de Economia).

; BELLUZZO L. G. Desenvolvimento no Brasil - relembrando um velho tema. In: BIELSHOWSKY, R.; MUSSI, C. (Org.). A política para a retomada do crescimento reflexões de economistas brasileiros. Brasília: Ipea/Cepal, 2002.

TEIXEIRA, A. O conceito de seguridade social e a Constituição de 1998. Previdência em Dados, Rio de Janeiro, (SE), v.7, 1992.

TITMUS, R. Essays on the Welfare State. London: Allen \&Unwin, 1963.

VIANNA, M. L. A americanização (perversa) da seguridade social no Brasil: estratégias de bem-estar e políticas públicas. 2 ed. Rio de Janeiro: Revan/Ucam/IUPERJ, 1998. 